AGH DRILLING, OIL, GAS • Vol. 32 • No. $1 \cdot 2015$

http://dx.doi.org/10.7494/drill.2015.32.1.175

\author{
Argentina Tătaru*, Dan Paul Ştefănescu*, Sándor Balázs*
}

\title{
IMPLEMENTATION OF PROJECT MANAGEMENT CONCEPT, IN DEPLETED GAS RESERVOIR EXPLOITATION
}

\section{INTRODUCTION}

In the past the gas industry focused its interest and major investments mainly on the early life of the reservoir and on the development and constant maintenance of production. But times change and currently mature gas reservoirs defined as reservoirs in an advanced stage of decline of reservoir energy and production should be considered as potential additional energy sources.

In an economic environment affected by increasing gas demand, great importance should be attached to mature reservoir production enhancement and extension of production, trying to maximize production decline and to postpone the end of production. There are complex reasons behind this approach that are imposed both by the need for resources and by management decisions, as well as by the possibility to reconsider geological model.

The overall objective of the proposed research is to determine optimal development strategies for depleted gas reservoirs. A specific objective is to develop technology and tools to help operators determine optimal well spacing and completion strategies in depleted gas reservoirs as quickly as possible.

Project management could be defined as the process of managing, allocating, and timing resources to achieve a given goal in an efficient and expeditious manner.

Real time reservoir management is a emergent concept in the exploration and production industry.

Reservoir management is based on a series of decisions that enables gas companies to meet their technical and business objectives. The process requires an accurate model of the reservoir system and the ability to predict the consequence of implementing possible, alternative solutions.

* SNGN ROMGAZ SA 
Depleted gas reservoirs are part of gas management and therefore it is important to identify the best method for optimize recovery at a effective cost, using the correct technology.

Since the objective in making predictions is to optimize productions, it may be necessary to take surface processing facilities into account.

Reservoir characterization is a continous process that must be updated as new information is gathered from the asset.

The primary goal of the project is to provide technology capability (technology and competence) to enable the company to efficiently produce from depleted gas reservoirs.

There are some companies in this domain that have a wrong perception related to mature reservoirs, which they consider to be synonymous with almost depleted reservoirs, involving less challenges as compared to new discoveries. Indeed most of world gas production comes from reservoirs discovered a long time ago, their acute problems being related to economic viability of production during production decline and increase of final recovery factor. The ideal time to start managing a reservoir is at its discovery, but Romgaz has a new approach regarding project management implemenatation for depleted gas fields [1].

\section{GENERAL CONCEPT OF PROJECT MANAGEMENT}

Reservoir management requires team efforts, integration, multidisciplinary, and the involved players in this demarche (step) are all those who are in contact with the reservoir.

Gas reservoirs management assume those approaches which leads to maximization of gas recovery, through a economical optimization, by using all the available resources (human, technology and financial), and discusses how rigorous and disciplined application of project management tools and techniques can help mitigate technical, managerial, and human resources challenges. For a successfull management it is necessary a integrated approach between human resources, technologies, equipments and informations, and for a real interaction among them.

The project management success depends on:

- understanding of the entire project management proccess, including from technologies and equipments point of view,

- opening, flexibility, communication and coordination,

- team-work,

- perseverance [3].

The developement and operation decisions must be established by the entire reservoir management team, which must recognize the dependency of the whole system towards the nature and reservoir behaviour. It is not necessary that all the decisions to be taken by a reservoir engineer, because any member of the team who takes in consideration the reservoir under all its aspects, will be a more efficient decisional factor. It is also beneficial if 
the respective person has knowledge about reservoir engineering, geology, production and drilling, well and functioning, and not least about surface facilities.

Generally, in most of the companies, a few people have knowledge in all the fields, but many persons develop a intuition on the entire system and know when to ask for technical advices regarding the different elements of the system. It is difficult for anyone to become an expert in all of the fields, especially in conditions of appearence of some complex technologies.

So, it is obvious that the reduction of talents and the development of complex technologies must be compensate by rising quality, productivity and increasing team effort.

The importance of depleted gas reservoirs management is obvious at actual context, in which the exploitation introduction rhytmicity of new reservoirs does not counterbalance the mature reservoirs decline.

The team members must work together to assure the development and the execution of the management plan. By crossing traditional boundaries and integrating their functions, the companies resources are better used for achieving their common goal.

The strategy presumed, a multidisciplinary team of geophysicists, geologists, reservoir engineers, production engineers, economists and legal.

\section{IMPLEMENTING PROJECT MANAGEMENT IN ROMGAZ}

Starting from the previously presented concept, Romgaz implemented this boarding for a lot of depleted gas reservoirs. In Figure 1 is presented a scheme with the structure of the team which assures the management for some of the gas depleted reservoirs.

These multidisciplinary teams evaluate existing information and build up a plan for new data acquisitions, the datas were integrated, processed, interpreted and correlated in a study with following objectives:

- Construct 3D geological model to estimate resources.

- Use reservoir engineering to estimate remaining reserves and expected ultimate recovery.

- Use results of the study to identify new development opportunities on the field and forecast production scenarios [2].

To be effective, a project team must be able to make things happen, which is best accomplished by maintaining a can do attitude and working together as an integrated team. Effective teamwork is mandatory for bringing any management project under control.

Because each wells from each objectives are unique, the project team must be assembled, organized, and managed for the particular conditions. The project manager must assemble a team of people who have the right technical expertise to handle the job. He must be the leader of the team of individuals with diverse backgrounds and with special expertise to handle any problems that arise. 


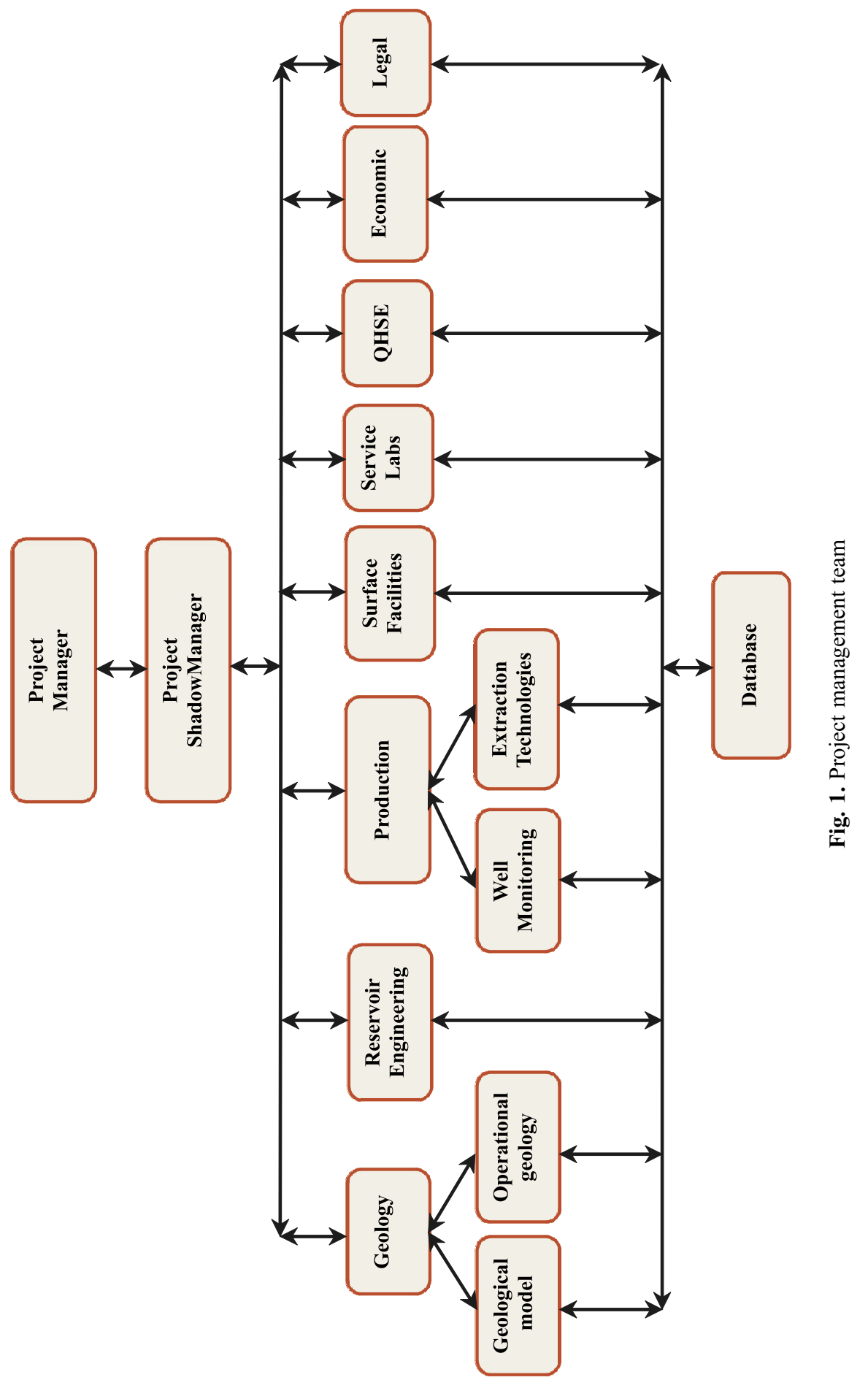


Although a formal system of handling the project is needed, it is people that make things happen, and these people must have the ability to detect problems, make adjustment to the system, and make the right decisions at the right time.

The main purpose of these management projects represents to increase the final recovery factor for gas reserves.

This desideratum will be realized through:

- monitoring exploitation parameters,

- reconsideration of the obtained informations from the existing geophysical investigations, corelated with the new informations,

- implementation of the most adequate extraction technologies,

- exploitation optimization of the layer - well system,

- identification of some future developing posibilities depending on the new obtained informations.

The management projects beeing in progress are based on the following flux diagram (Fig. 2).

Although each well control project is unique, a well-managed project generally follows this sequence:

- the team must define the scope of what must be accomplished, including giving priorities tp tasks, identifying equipment and special expertise, and setting expected levels of quality, safety requirements, and reliability of operations;

- although budget is often not a controlling factor in well control projects, eventually the allocation and responsibility of cost expenditures must be addressed, including budgeting each task in the scope definition;

- a strategy must be set for accomplishing the tasks, it is important to anticipate all events and to build contingency plan into the project for the unexpected deviations that often occur;

- a timetable must be made for the planned work to ensure an integrated sequence of all tasks;

- a tracking system must be developed to ensure the project progresses as planned, by measuring actual work done versus the schedule;

- the project should be closed aut, which includes verification that all required tasks have been completed to ensure the project is in a stable condition and completed at an acceptable level of quality [4].

These steps represent project management in its simplest form. In practice, there is considerable overlap in the sequence because there are many parties involved, and the work of one may affect the work of the others. Thus, extensive coordination is required.

The most important task for any project is to define the scope of work. A fundamental principle of project management is that any project, regardless of its size or type, consists of three components: scope, budget and schedule. Each of these components must be described in detail and linked to the others. For example, as the scope of work increases, the cost and time to do the work will also increase. 


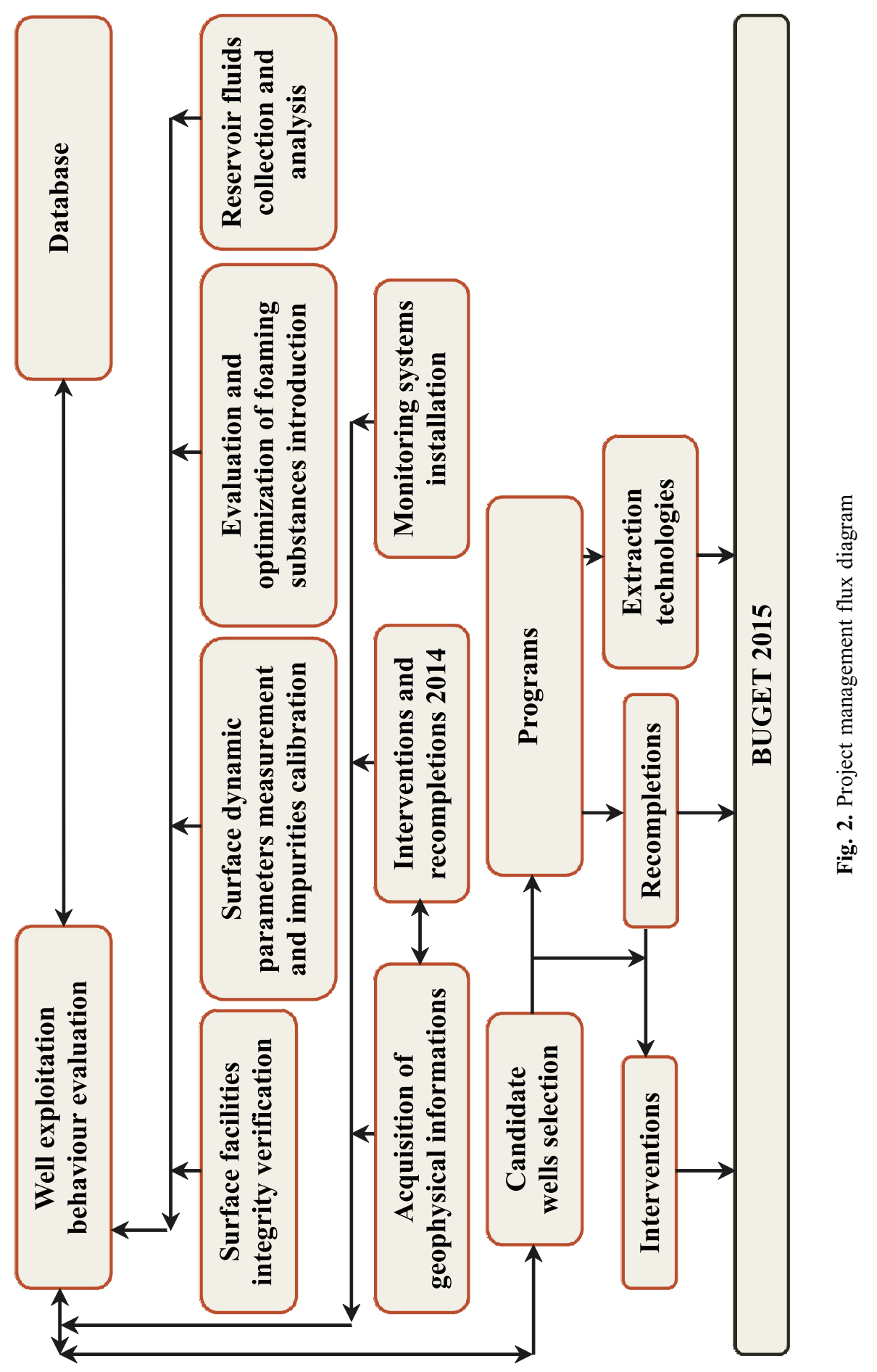


Defining the project scope must precede defining the budget or the schedule.

The project manager must have the technical knowledge of what needs to be done and the agility to communicate that knowledge to others.

The central axiom for project management is to organize the project around the work to be done rather than trying to force events to fit some predetermined organization.

The depleted gas reservoirs management presume:

- validation of the existent informations about the reservoirs, wells, surface facilities, production parameters,

- acquisition of new informations,

- corelation and evaluation of all the informations,

- engendering of some development strategies for the reservoir.

In this sense it was operated on the following segments:

- evaluation of well exploitation behaviour,

- verification of well integrity and surface facilities integrity,

- monitoring surface dynamic parameters and impurities,

- evaluation and optimization of foaming substances introduction,

- collecting and analysing reservoir fluids,

- acquisition of new geophysical informations,

- installation of new monitoring systems,

- selection of the wells candidate for the jobs,

- elaboration of technical programs,

- cash - flow analysis,

- elaboration of the budget for the in progress year.

As the paper title mentions, gas reservoirs are in different depletion stages which induces different exploitation behaviour of the wells.

This requires the application of some evaluation and selection criterias for gas wells candidate for the different jobs.

The selection criterias for wells candidate for the jobs consist from:

- Selection criterias for work - over jobs:

- inactive wells,

- wells with technical accidents,

- abandoned wells with reactivation posibilities,

- wells with dual exploitation posibilities,

- wells with addition posibilities within the same objective.

- Selection criterias for rigless jobs:

- wells with high differences $\mathrm{Pt} / \mathrm{Pc}$,

- wells with plugged tubing and perforations,

- wells with the tubing fixed at the base of the perforations or under the perforations,

- wells with relative high static pressures and low flow rates, 
- wells with addition posibilities,

- wells with low productivity which produce from the same complex with high productivity wells,

- wells that requires christmas tree replacement.

- Selection criterias for coiled tubing jobs:

- wells whitch applications including matrix and fracture stimulation, wellbore cleanout, logging, perforating, nitrogen kickoff, sand control, drilling, cementing, well circulation, and mechanical isolation.

All the obtained informations will be centralized in a database, which will contain the following:

1. Geological data:

- geological model,

- geophysical datas,

- core analysis.

2. Reservoir data:

- dynamic model,

- reservoir measurements,

- reservoir fluids analysis,

- production tests.

3. Production data:

- Geographic Information System (GIS),

- foaming substances introduction programs.

4. Well construction and completion:

- well construction,

- completion history,

- special events.

5. Surface facilities:

- christmas trees,

- pipeline,

- well groups,

- compressors (gas compression stations),

- drying stations (gas dehydration stations),

- rezidual water injection systems.

6. Technical programs for wells.

7. Economical data:

- cash - flow analysis,

- economical analysis,

- budget.

8. QHSE procedures.

9. Well events. 


\section{CONCLUSIONS}

The main purpose of reservoir project management is to control operations with maximizing the recovery factor for obtaining maximum economic recovery possible from a reservoir, based on facts, informations and knowledge.

The size and complexity of these jobs require special attention in the project management process. Risks are a big part of these projects, thus more attention needs to be paid for planning, organization, control and contingencies.

Project management defines a process of managing, allocating and timing resources to achieve a given goal in an efficient and expeditious manner.

The objectives that constitute the specified goal may be in terms of time, costs or technical results.

All major industries are touched by global challenges, including gas industry as well, which has a direct role to play, because energy is the foundation for accomplishing the given goals.

This requires the application of project management tools and techniques to bring about new services and results efficiently within cost and schedule constrains.

Project management is one avenue through which we can ensure that the desired services and results can be achieved. With the positive outcome of these projects, we can improve the quality of the exploitation reservoirs, by maximizing final recovery factor and increasing economical rentability.

\section{REFERENCES}

[1] Tătaru A., Dobrescu D., Costin N.: Managementul zăcămintelor de gaze naturale mature - o abordare curentă. Monitorul de Petrol şi Gaze, Nr. 7, Anul. X, 2012.

[2] Ştefănescu D.P., Tătaru A., Popa A.M.: Romgaz reservoir management concept - synergy and team - 150 Years of the Romanian Petroleum Industry, Tradition \& Challenges. Bucharest, Romania, 14-17 October 2007.

[3] Stoicescu C.C.: Management - Teorii şi tehnici. Editura Universităţii Ploieşti, 2006.

[4] Adedeji B.B., Osisanya S.O.: Project management for the oil and gas industry. CRC Press, Taylor \& Francis, 2013. 